\title{
Rekomendasi Pemupukan K Spesifik Lokasi Untuk Tanaman Padi Sawah
}

DOI 10.18196/pt.2014.022.44-48

\author{
I Made Adnyana
}

Jurusan Tanah, Fakultas Pertanian, Universitas Udayana, Jl. Kampus Unud, Bukit Jimbaran, Kuta Selatan, Badung e-mail:adnyanamade99@yahoo.com

\begin{abstract}
ABSTRAK
Efisiensipenggunaanpupuksangat tergantung pada sifat-sifat tanah, jenis pupuk, irigasi dan keintensifan tingkat budidaya.Penelitian Kalium Spesifik Lokasi dilakukan untuk merumuskan rekomendasi pemupukan K untuk tanaman padi dalam status K tanah yang berbeda. Tujuan dari penelitian ini adalah untuk memilih metode uji tanah yang tepat, mengklasifikasikan nilai uji tanah dari K menjadi dua atau lebih kelas dan rekomendasi pemupukan K untuk tanaman padi. Hasil penelitian menunjukkan bahwa metode $\mathrm{NH}_{4} \mathrm{OAc} 1 \mathrm{~N}$ pH 7 adalah teknik terbaik untuk analisis tanah. Berdasarkan metode tersebut, ada 3 kelas ketersediaan K yaitu rendah, sedang dan tinggi. Tanah dengan ketersediaan K tinggi tidak memerlukan pemupukan dengan K, karena telah dipenuhi oleh air irigasi dan jerami. Rekomendasi pemupukan K untuk tanaman padi di tanah dengan kelas K sedang lebih rendah dari tanah dengan kelas $\mathrm{K}$ rendah.

Kata kunci : Spesifik lokasi, Kalium, Tanah Sawah, Metode NH4OAc 1 N pH 7
\end{abstract}

\section{ABSTRACT}

The efficiency of fertilizer use is changing greatly depending on soil properties, fertilizer type, irrigation and level of intensive cultivation. A site specific potassium $(K)$ experiment was conducted to formulate the fertilizer recommendation of $K$ for rice plant in different $K$ soil status. The objective of this research were to select a proper soil test method, classify the soil test value of $K$ into two or more classes and fertilizer recommendation of $K$ to rice plant. The result showed that the method of $\mathrm{NH}_{4} \mathrm{OAC} 1 \mathrm{~N} \mathrm{pH} 7$ was the best technique for soil analysis. Based on the method, there are 3 available classes of Ki.e. low, medium and high. The soil with the highest availability of K does not require fertilizing with K, because it has been fulfilled by the water irrigation and straw. The fertilizer recommendation of $K$ for rice plant at medium class is less than low class.

Keywords : site specific, potassium, paddy soil, $\mathrm{NH}_{4} \mathrm{OAc} 1 \mathrm{~N} \mathrm{pH} 7$ method.

\section{PENDAHULUAN}

Perkembangan teknologi pertanian yang sangat pesat pada tanah sawah dapat menyebabkan penurunan hara dalam tanah, dan untuk mengatasinya serta memacu peningkatan hasil padi sawah, dilakukan dengan pemupukan. Sofyan et al. (2002), menyatakan bahwa rekomendasi pemupukan kalium didasarkan pada filosofi yaitu pada tanah yang berstatus $\mathrm{K}$ sedang dan tinggi tidak perlu diberi pupuk $\mathrm{K}$ karena kebutuhan $\mathrm{K}$ padi sawah pada tanah tersebut sudah dapat dipenuhi dari K tanah, air irigasi, dan pengembalian jerami.

Penggunaan pupuk anorganik meluas sejak tahun 1969,yaitu saat dimulainya
programBimas. Pada mulanya hanya terbatas pada pupuk $\mathrm{N}$ dan $\mathrm{P}$ saja, tetapi beberapa tahun berikutnya mulai digunakan pupuk K. Semenjak diberlakukan kebijakan pencabutan subsidi pupuk oleh pemerintah, menyebabkan harga pupuk semakin mahal dan terjadi kelangkaan pupuk di beberapa tempat di lapangan, sehingga takaran pupuk yang digunakan petani sangat bervariasi tergantung dari daya belinya. Umumnya petani dalam menggunakan pupuk lebih banyak mempertimbangkan faktor sosial ekonomi dibandingkan dengan faktor biofisika kimia. Penggunaan pupuk secara tepat adalah salah satu faktor kunci untuk dapat 
mempertahankan produktivitas tanah sawah, di samping akan sangat menguntungkan baik secara teknis, ekonomis, maupun lingkungan.

Kalium (K) merupakan unsur pupuk selain nitrogen $(\mathrm{N})$, dan fosfor $(\mathrm{P})$ yang perlu diperhatikan pemanfaatannya. Walaupun penggunaan pupuk $\mathrm{K}$ secara nyata mampu meningkatkan hasil padi sawah akan tetapi penggunaan pupuk tersebut dalam konsentrasi tinggi akan dapat mengikat unsur lain menjadi senyawa kompleks yang tidak larut. Macammacam kompleks anorganik yang terbentuk antara lain $\mathrm{Cu} \mathrm{KH}\left(\mathrm{PO}_{4}\right)_{2}$ dan $\mathrm{Zn} \mathrm{KH}\left(\mathrm{PO}_{4}\right)_{2}$ (Reichardt et al., 2001 dan Nguyen Van Bo, 2002). Di lain pihak, apabila penggunaan pupuk $\mathrm{K}$ seadanya saja disertai dengan penanaman yang intensif akan dapat menguras hara tersebut dengan cepat dari dalam tanah sehingga hasil maksimal tanaman padi tidak mungkin dapat dicapai.

Rekomendasi pemupukan K untuk padi sawah yang dilakukan pemerintah saat ini masih bersifat umum tanpa mempertimbangkan kandungan hara $\mathrm{K}$ dalam tanah dan kebutuhan tanaman. Agar pemupukan K lebih efisien, perlu perbaikan rekomendasi pemupukan yang berlaku saat ini menjadi pemupukan spesifik lokasi yang didasarkan pada uji tanah dan analisis tanaman. Nilai uji tanah untuk setiap tanah dan tanaman akan berbeda-beda, berarti bahwa rekomendasi pemupukan yang dilaksanakan akan berbeda-beda pula, atau spesifik untuk suatu lokasi. Juang et al. (2002) menyatakan bahwa pemupukan spesifik lokasi adalah pemupukan yang bersifat spasial dengan tujuan untuk mengoptimalkan hasil dan meminimalkan kehilangan hara yang dikandung pupuk yang bersangkutan. Sementara itu menurut Puslittanak (2000), rekomendasi pemupukan spesifik lokasi didasarkan pada sistem iklim-tanah-tanaman, dan ekstrapolasi rekomendasi pemupukan dapat dilaksanakan pada tingkat famili atau kelompok famili tanah.

Rekomendasi pemupukan K spesifik lokasi dapat dirumuskan melalui serangkaian kegiatan sistematis sebagai berikut (Adiningsih et al., 2000 Khaderni dan Malakouti, 2001): (1) Survai status hara $\mathrm{K}$ dalam tanah, untuk perencanaan alokasi pemupukan K, (2) Studi korelasi, untuk mengetahui hubungan antara konsentrasi unsur $\mathrm{K}$ yang dapat diekstrak oleh suatu metode uji tanah tertentu dengan jumlah hara $\mathrm{K}$ yang dapat diserap tanaman, (3) Studi kalibrasi, untuk mengetahui hubungan antara hasil analisis hara $\mathrm{K}$ dengan respons tanaman, dan penentuan kelas ketersediaan hara K, (4) Interpretasi hasil analisis tanah, untuk menilai staus $\mathrm{K}$ tanah, (5) Penyusunan rekomendasi pemupukan $\mathrm{P}$ berdasarkan analisis tanah dan tanaman pada setiap kelas ketersediaan hara $\mathrm{K}$.

Penelitian dilaksanakan dengan tujuan tersusunnya rekomendasi pemupukan $\mathrm{K}$ yang direvisi dari pemerintah menjadi pemupukan $\mathrm{K}$ spesifik lokasi dalam budidaya tanaman padi sawah yang hasilnya dapat mensuplai kebutuhan beras dalam negeri.

\section{BAHAN DAN METODE}

Penelitian dilakukan di laboratorium Tanah, Fakultas Pertanian, Universitas Udayana, Denpasar, dan penelitian lapangan pada tanah yang memiliki subgroup sama di beberapa subak yang terdapat di kabupaten Tabanan, Bali.

\section{Survai Status Hara K dalam Tanah}

Contoh tanah diambil dengan sistem grid dengan memperhatikan fisiografi dan jenis tanah. Setiap 25 ha sawah diambil satu sampel tanah secara komposit. Contoh tanah tersebut 
dikering-udarakan dan diayak dengan saringan 2 $\mathrm{mm}$, selanjutnya dianalisis kadar $\mathrm{K}$ potensial dengan metode $\mathrm{HCl}-25 \%$, menggunakan alat fotometer nyala. Hasil analisis dikelompokkan menjadi 3 yaitu : status $\mathrm{K}$ rendah $(<10 \mathrm{mg} \mathrm{Kp}$ $\left.100 \mathrm{~g}^{1}\right)$, status $\mathrm{K}$ sedang (10-20 mg Kp $\left.100 \mathrm{~g}^{-1}\right)$, dan status $\mathrm{K}$ tinggi (>20 mg Kp $100 \mathrm{~g}^{1}$ ).

\section{Percobaan Lapangan}

Percobaan lapangan dilakukan diKabupaten Tabanan, pada lokasi yang memiliki status $\mathrm{K}$ tanah berbeda, tetapi berada pada subgroup yang sama (Aquik tropaqueppts). Percobaan taraf pemupukan $\mathrm{K}$ pada setiap status $\mathrm{K}$ tanah disusun dengan Rancangan Acak Kelompok (RAK) dengan 4 ulangan, dan dianalisis dengan combined experiment(Gomez dan Gomez, 1995). Taraf pupuk P terdiri dari 0, 10,83, 21,66, 32,49, 43,32, dan $54,15 \mathrm{~kg} \mathrm{ha}^{-1} \mathrm{~K}$. Status K terdiridari rendah, sedang, dan tinggi, yang masing-masing ada di Subak Celebuh, Wanasari, Tabanan; Subak Saih, Kukuh, Marga; danSubak Senapahan, Banyar Anyar, Kediri.

Dalam percobaan ini diperlukan 72 petak percobaan masing-masing dengan ukuran $5 \times 6$ $\mathrm{m}$, jarak tanam $20 \times 20 \mathrm{~cm}$, dengan 2 rumpun bibit per lubang. Pupuk dasar berupa $250 \mathrm{~kg}$ urea ha ${ }^{-1}$ dan $100 \mathrm{~kg} \mathrm{ha}^{-1}$ SP-36. Pada umur 45 hari setelah tanam diambil contoh tanaman sebanyak 4 rumpun per petak untuk analisis kadar P tanaman. Selanjutnya panen dilakukan pada umur 105 hari, dan dilakukan pengukuran bobot basah dan kering gabah.

\section{Penetapan Ketersediaan K}

Kadar $\mathrm{K}$ tanah ditetapkan dengan berbagai metode analisis, yaitu $\mathrm{HCl}-25 \%$, Olsen, Bray-I, dan $\mathrm{NH}_{4} \mathrm{OAc} 1 \mathrm{~N}$ pH 7. Hasil analisis dikorelasikan dengan kandungan $\mathrm{K}$ tanaman dan bobot gabah. Metode analisis yang berkorelasi tinggi dengan respons tanaman dinilai sebagai metode analisis ketersediaan hara $\mathrm{K}$ terbaik.

\section{Penentuan Kelas Ketersediaan Hara K}

Kelas ketersediaan hara $\mathrm{K}$ yang ditetapkan dengan metode analisis ketersediaan hara $\mathrm{K}$ terbaik ditentukan dengan metode keragaman Nelson dan Anderson (Nursyamsi et al., 1993). Ketersediaan hara $\mathrm{K}$ dikelompokkan menjadi 35 kelas, tergantung hasil analisis.

\section{Penyusunan Rekomendasi Pemupukan K}

Penyusunan rekomendasi pemupukan $\mathrm{K}$ dilakukan dengan bantuan kurva respon, melalui metode kuadratik (Draper dan Smith, 1992). Dari kurva tersebut ditetapkan takaran pupuk tertinggi, yaitu takaran pupuk untuk menghasilkan hasil maksimum (100\%) dan takaran pupuk terendah, yaitu diasumsikan sebagai takaran pupuk yang dengan takaran sebesar itu hasil mencapai 90\%.

\section{HASIL DAN PEMBAHASAN}

\section{Status K Tanah}

Kadar $\mathrm{K}_{2} \mathrm{O}$ tanah sawah di Kabupaten Tabanan, bervariasi dari rendah sampai tinggi, berkisar antara 2,75-100 mg $100 \mathrm{~g}^{1}$ Rata-rata kadar $\mathrm{K}_{2} \mathrm{O}$ disajikan pada Tabel 1 . Sebanyak 54\% tanah tersebut berstatus $\mathrm{K}$ tinggi, 38\% berstatus $\mathrm{K}$ sedang, dan $8 \%$ berstatus $\mathrm{K}$ tanah rendah. Sebagian besar tanah berstatus K tinggi, karena ada hubungannya dengan jenis tanah yang dominan di Kabupaten Tabanan, yaitu Inseptisols (65,07\%). Diduga K yang tinggi pada Inseptisols tersebut, di samping berasal dari mineral pembentuk tanah, juga dari pelapukan jerami, air irigasi, serta cadangan $\mathrm{K}$ yang tinggi akibat KTK dan KB yang tinggi (Sofyan et al. 2002 dan Lanya, 1999). 
Tabel 1. Kadar Rata-Rata, Kisaran, dan Simpangan Baku $\mathrm{K}_{2} \mathrm{O}$ Ekstrak Hcl-25\% Pada Status K Berbeda Di Kabupaten Tabanan, Bali

\begin{tabular}{|c|c|c|c|c|c|c|}
\hline \multirow{2}{*}{ Ciri Kimia } & \multirow{2}{*}{ Status Hara } & \multirow{2}{*}{ Jumlah Contoh } & \multirow{2}{*}{ Kadar Rata-rata } & \multicolumn{2}{|c|}{ Kisaran } & \multirow{2}{*}{ Simpangan baku } \\
\hline & & & & Terendah & Tertingqi & \\
\hline \multirow{4}{*}{$\mathrm{K}_{2} \mathrm{O}$} & & & $\mathrm{Mg} 100 \mathrm{~g}^{-1} \mathrm{~K}_{2} \mathrm{O}$. & & & \\
\hline & Rendah & 63 & 8,64 & 2,75 & 9,90 & 8,40 \\
\hline & Sedang & 265 & 15,60 & 10,00 & 19,95 & 2,70 \\
\hline & Tinggi & 442 & 31,76 & 20,00 & 100,00 & 13,32 \\
\hline
\end{tabular}

Tabel 2. Nilai Koefisien Korelasi (R) Antara Beberapa Metode Ekstraksi Uji Tanah Dengan Respon Hasil

\begin{tabular}{llll}
\hline METODE & \multicolumn{3}{c}{ Respon Hasil (\%) } \\
\cline { 2 - 4 } EKSTRAKSI & Bobot Gabah & Kadar K Tanaman & Kandungan K Tanaman \\
\hline Olsen & $0,90^{* *}$ & $0,74^{* *}$ & $0,73^{* *}$ \\
Bray-1 & $0,92^{* *}$ & $0,87^{\text {ns }}$ & $0,66^{*}$ \\
HH $_{4}$ OAc 1 N pH 7 & $0,97^{* *}$ & $0,82^{* *}$ & $0,87^{* *}$ \\
HCl-25\% & $0,89^{* *}$ & $0,77^{* *}$ & $0,77^{*}$ \\
\hline
\end{tabular}

Tabel 3. Penyusunan Rekomendasi Pemupukan K Pada Kelas Ketersediaan Hara K Berbeda Menurut Metode $\mathrm{NH}_{4} \mathrm{OAc} 1 \mathrm{~N} \mathrm{pH} 7$ Melalui Persamaan Kuadratik $\left(\mathrm{Y}=\mathrm{a}+\mathrm{bx}+\mathrm{cx}^{2}\right)$

\begin{tabular}{|c|c|c|c|c|c|c|c|c|}
\hline \multirow{2}{*}{$\begin{array}{l}\text { Kelas ketersediaan } \\
\text { hara K }\end{array}$} & \multirow[t]{2}{*}{ a } & \multirow[t]{2}{*}{ b } & \multirow[t]{2}{*}{ c } & \multirow[t]{2}{*}{$R^{2}$} & \multicolumn{4}{|c|}{$\begin{array}{l}\text { Takaran Pupuk }\left(\mathrm{Kg} \mathrm{ha}^{-1}\right) \\
\text { Tertinagi } \quad \text { Terendah }\end{array}$} \\
\hline & & & & & K & $\mathrm{KCl}$ & K & $\mathrm{KCl}$ \\
\hline Rendah & 3389,04 & 34,60 & 0,23 & 84,79 & 30 & 75 & 20 & 45 \\
\hline Sedang & 4024,20 & 29,80 & 0,23 & 80,44 & 28 & 65 & 15 & 35 \\
\hline Tinggi & 5294,18 & 5,77 & 0,03 & 17,88 & $\left.{ }^{*}\right)$ & $\left.{ }^{*}\right)$ & $\left.{ }^{*}\right)$ & $\left.{ }^{*}\right)$ \\
\hline
\end{tabular}

Keterangan : *) Tidak perlu dipupuk, karena melalui persamaan Mitscherlich dan Bray hanyadibutuhkan $8 \mathrm{~kg} \mathrm{KCl} \mathrm{ha}^{-1}$ atau dapat diabaikan

\section{Penetapan Metode Ketersediaan K Tanah}

Metode $\mathrm{NH}_{4} \mathrm{OAc} 1 \mathrm{~N}$ pH 7 adalah metode terbaik dalam analisis ketersediaan $\mathrm{K}$ tanah karena di samping mempunyai nilai koefisien korelasi tinggi dengan semua variabel respon (Tabel 2), juga sederhana dalam prosedur penetapan, filtrat yang dihasilkan dapat digunakan untuk penetapan unsur hara lainnya, dan lebih efisien ditinjau dari kaidah ekonomi.

Metode $\mathrm{NH}_{4} \mathrm{OAc} 1 \mathrm{~N}$ pH 7 sangat baik digunakan pada tanah sawah yang netral dan alkalin akibat penggenangan. Kondisi tersebut menyebabkan kompleks adsorpsi didominasi oleh kation-kation seperti $\mathrm{Ca}, \mathrm{Mg}, \mathrm{Na}$, dan $\mathrm{K}$. Ion $\mathrm{NH}_{4}^{+}$dapat menukar posisi kation-kation tersebut pada kompleks adsorpsi sehingga mereka menjadi bebas dan dapat diukur jumlahnya.

\section{Penetapan Kelas KetersediaanHaraK}

Hasil analisis statistika menunjukkan bahwa terdapat tiga kelompok kelas ketersediaan hara $\mathrm{K}$ dalam tanah atau tiga tingkat kelas ketersediaan hara K. Kelompok I, II, dan III masing-masing mencerminkan kelas ketersediaan hara $\mathrm{K}$ tanah rendah, sedang, dan 
tinggi. Batas kadar K-tersedia tanah menurut metode $\mathrm{NH}_{4} \mathrm{OAc} 1 \mathrm{~N}$ pH 7 yang rendah adalah< $200 \mathrm{mg} \mathrm{kg}^{1}$, sedang 200-227 $\mathrm{mg} \mathrm{kg}^{1}$ dan tinggi $>227 \mathrm{mg} \mathrm{kg}^{-1} \mathrm{Kriteria}$ tersebut merupakan batas rendah, sedang, dan tinggi respons tanaman padi sawah terhadap pemupukan K. Kelompok I, II, dan III tersebut berada pada kelompok yang sama dengan status $\mathrm{K}$ tanah yang rendah, sedang, dan tinggi.

\section{Penyusunan Rekomendasi Pemupukan K}

Data bobot gabah (14\% air) digunakan untukmenduga kurvarespons pemupukan (Tabel 3). Pada kelas ketersediaan hara $K$ tanah rendah diperlukan pupuk K lebih tinggi (16,11\%)

dibandingkan dengan kelas ketersediaan hara $\mathrm{K}$ tanah sedang. Tanah dengan kelas ketersediaan hara $\mathrm{K}$ tinggi, tidak diperlukan tambahan pupuk $\mathrm{K}$, karena menurut perhitungan berdasar persamaan Mitscherlich-Bray hanya diperlukan $8 \mathrm{~kg} \mathrm{ha}^{-1} \mathrm{KCl}$. Takaran sebesar itu dapat dipenuhi dari tanah, air irigasi, atau jerami.

\section{SIMPULAN}

Status K tanah sawah di Kabupaten Tabanan, Bali, beragam, yaitu rendah, sedang, dan tinggi. Metode $\mathrm{NH}_{4} \mathrm{OAc} 1 \mathrm{~N}$ pH 7 merupakan metode terbaik dalam analisis ketersediaan hara $\mathrm{K}$ tanah sawah, dan berdasarkan metode tersebut ditemukan3 kelas ketersediaan hara.Rekomendasipemupukan $\mathrm{K}(\mathrm{KCl})$ lebih tinggi pada kelas (status) $\mathrm{K}$ tanah yang lebih rendah, namun pada tanah sawah dengan status $\mathrm{K}$ tanah tinggi tidak direkomendasikan menggunakan pupuk tersebut.

Pada tanah dengan status $\mathrm{K}$ tinggi, meskipun tidak memerlukan pupuk K, untuk perawatan guna mempertahankan produktivitas tanah jangka panjang, sebaiknya hanya diberikan pupuk sesuai perhitungan Mitscherlich-Bray atau melalui pemanfaatan pupuk organik (jerami).

\section{DAFTAR PUSTAKA}

Adiningsih, J.S., D. Santoso, D. Setyorini, dan D. Nursyamsi. 2000. Program pembinaan uji tanah: Studi korelasi dan kalibrasi uji tanah. Makalah Praktek Pengembangan Uji Tanah, Puslittanak, Badan Penelitian dan Pengembangan Pertanian, Departemen Pertanian, Bogor, 25 Sept-21 Okt 2000.

Draper, M. dan H. Smith. 1992. Analisis regresi terapan. Edisi kedua. P. T. Gramedia Pustaka Utama, Jakarta.

Gomez, K. A. dan A. A. Gomez. 1995. Prosedur statistik untuk penelitian pertanian. Edisi 2. Terjemahan. UI Press, Jakarta.

Juang, Kai-Wei., Day-Chyng Liou, and Dar-Yuan Lee. 2002. Site specific phosphorus aplication based on the kriging fertilizerphosphorus availability index of soils. J.Environ. Qual. 31 : 1248-1255.

Khaderni, Z., and M.J. Malakouti. 2001. Balanced fertilizer, an effective means of increasing crop resistance to diseases and pests. Prepared for the second national conference on optimum utilization of chemical fertilizers and pesticides in agriculture. A valaible at http://www.iranswari. comb/b/ khademi. htm. (Diakses tanggal 25 Februari 2002).

Lanya, I. 1999. Prospek pengembangan sektor pertanian di Bali berdasarkan sumberdaya lahan dan SDM. Lokakarya HUT XXXI Fakultas Pertanian, Universitas Udayana, Denpasar

Nguyen Van Bo. 2002. The role of fertilizer in modern agriculture production in Vietnam. p.1-9. In Fertilizer Information. Available at http//wwwfadinap.org/vietnam/ fertilizer.htm (Diakses tanggal 25Juli 2002).

Nursyamsi, D., D. Setyorini, dan I.P.G. Widjaja-Adhi. 1993. Penentuankelas haraP terekstrak beberapa pengekstrak dengan metode analisis keragaman yang dimodifikasi. p. 217236. Dalam Pros. Pertemuan Teknis Penelitian Tanah dan Agroklimat, Puslittanak, Badan Penelitian dan Pengembangan Pertanian, Departemen Pertanian, 18-21 Februari 1993.

Reichardt, W., A. Dobermann, and T. George. 2001. Intensification of rice production system: Opportunities and Limits. Fischer 1 , Chapter 3.htm. (2-16).

Sofyan, A., D. Nursyamsi and I. Amien 2002. Development of soil testing program in Indonesia. P. 10-25. In Workshop Proceding IRRI, Texas. A\&M University, and University of Hawai, 21-24 January 2002. 